\title{
Deposition of palladium nanoparticles by the coating of carbonaceous layer from wastepaper-derived bio-
}

\section{oil}

Tengyao Jiang, ${ }^{a, b}$ Yuan Yuan, ${ }^{b, c}$ Sijia Liu, ${ }^{a}$ Andrew J. Hunt ${ }^{* b \dagger}$ and Gang Tan*a

aDepartment of Civil and Architectural Engineering, University of Wyoming, 1000 E. University Avenue, Dept. 3295, Laramie, WY 82071, USA

${ }^{b}$ Green Chemistry Centre of Excellence, Department of Chemistry, University of York, YO10 5DD, UK

'Marine Agriculture Research Center, Tobacco Research Institute of Chinese Academy of Agricultural Sciences, Qingdao, 266101, China

$\dagger$ Present Addresses: Materials Chemistry Research Center, Department of Chemistry, Faculty of Science, Khon Kaen University, Khon Kaen, Thailand 


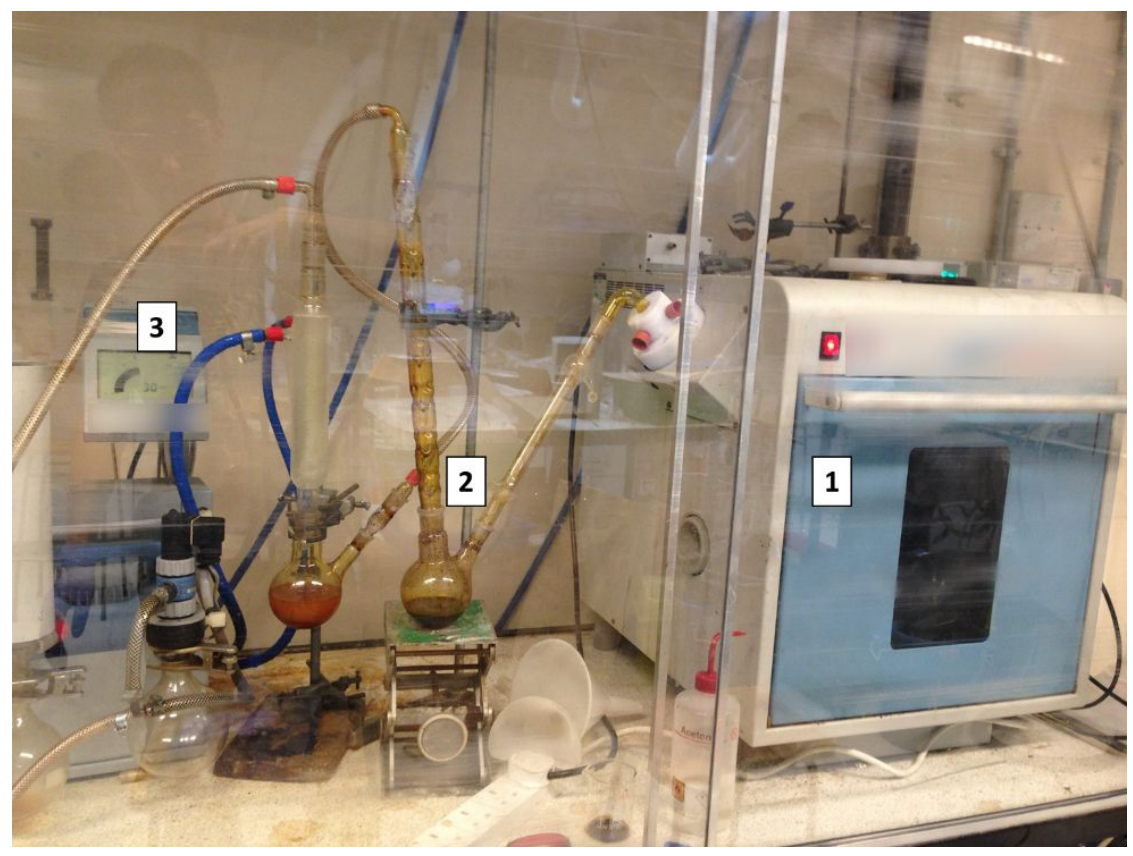

Figure S1 Set-up for microwave pyrolysis. (1) microwave reactor, (2) round bottom flask for collection of bio-oil, (3) vacuum pump

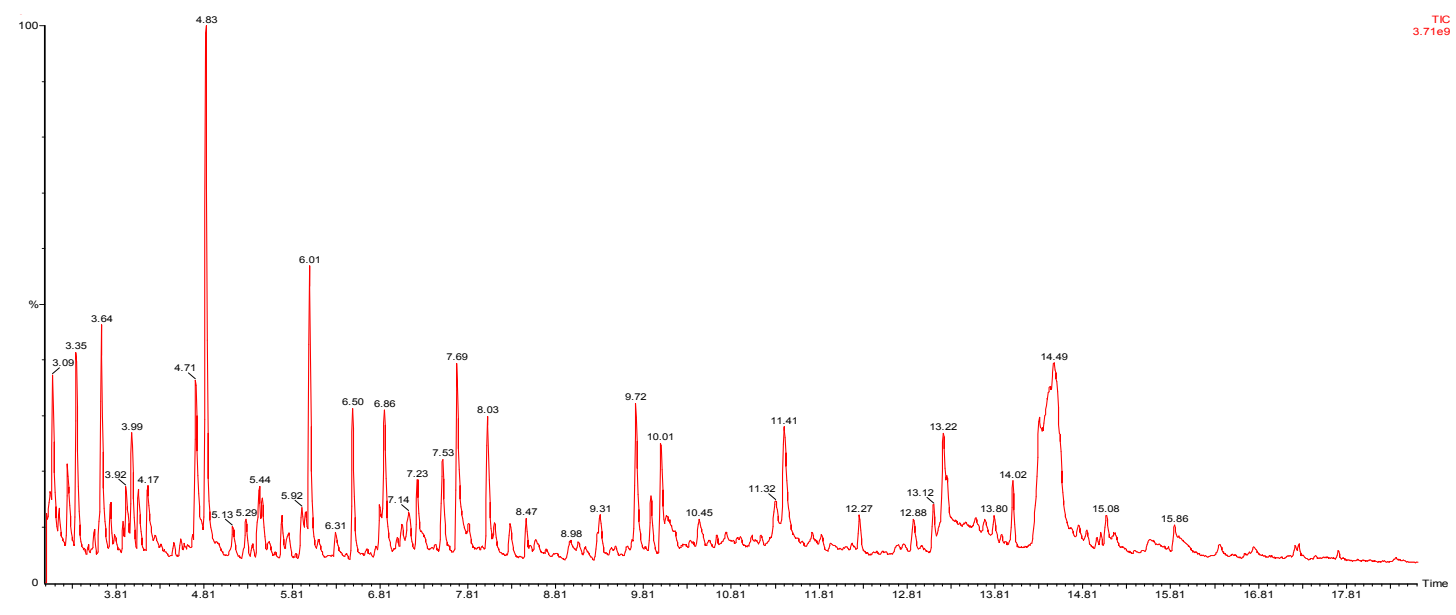

Figure S2 GC spectra of bio-oil pyrolyzed from wastepaper 


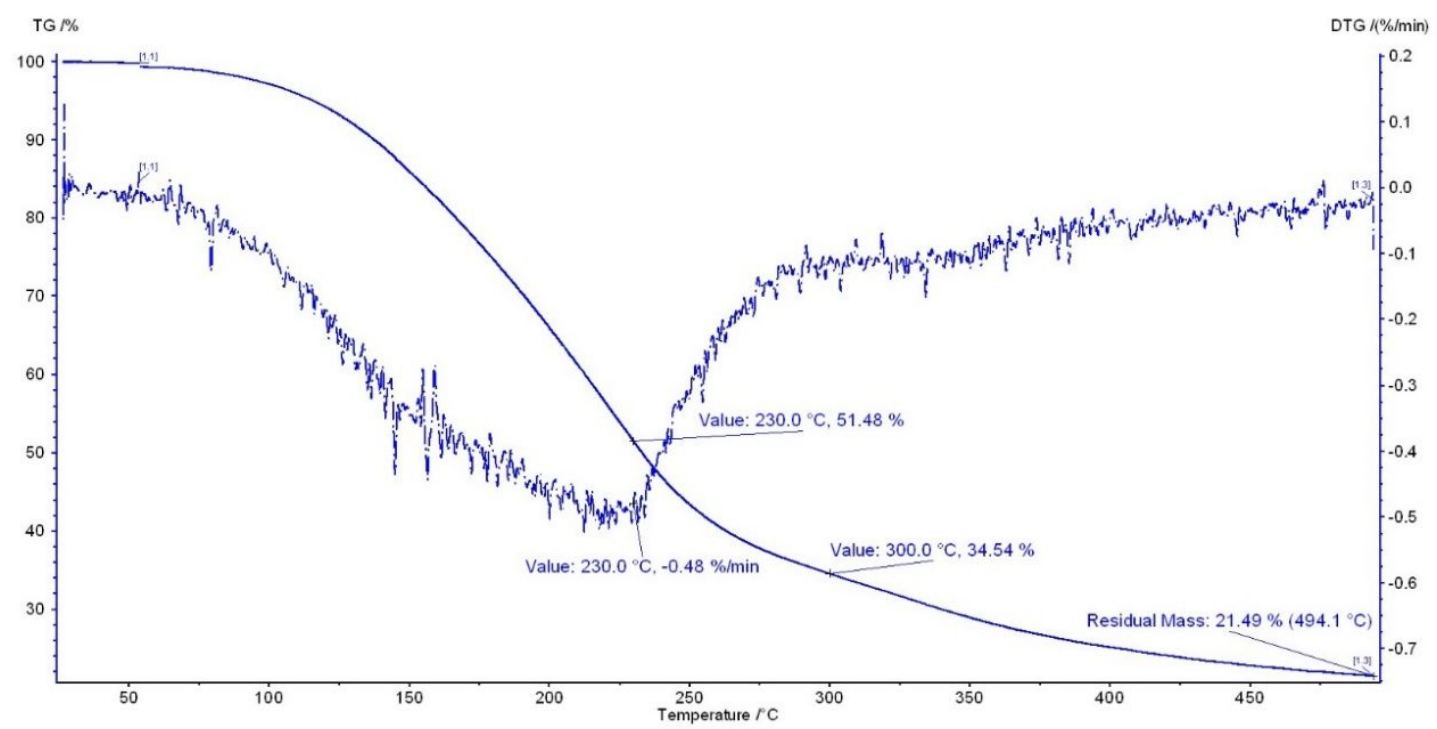

Figure S3 TG analysis of bio-oil sample

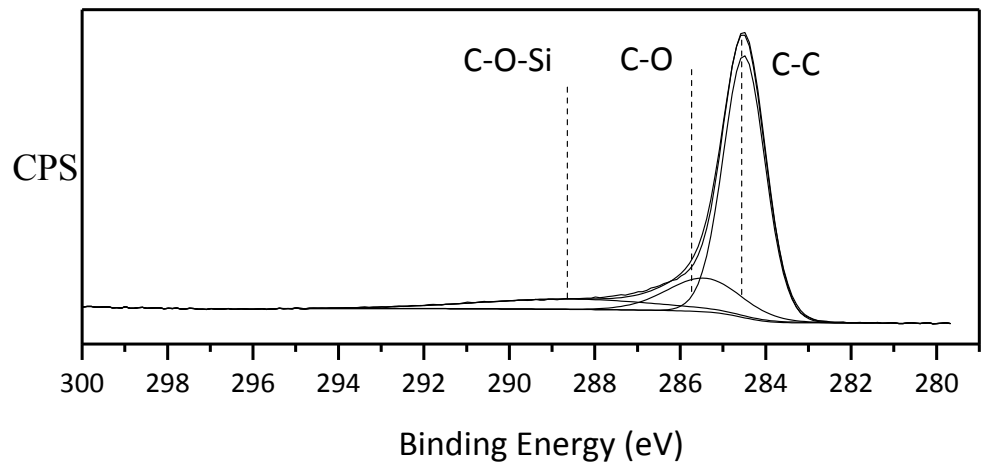

Figure $S 4 C_{1 s}$ XPS spectra of the $P-1$ catalyst sample 


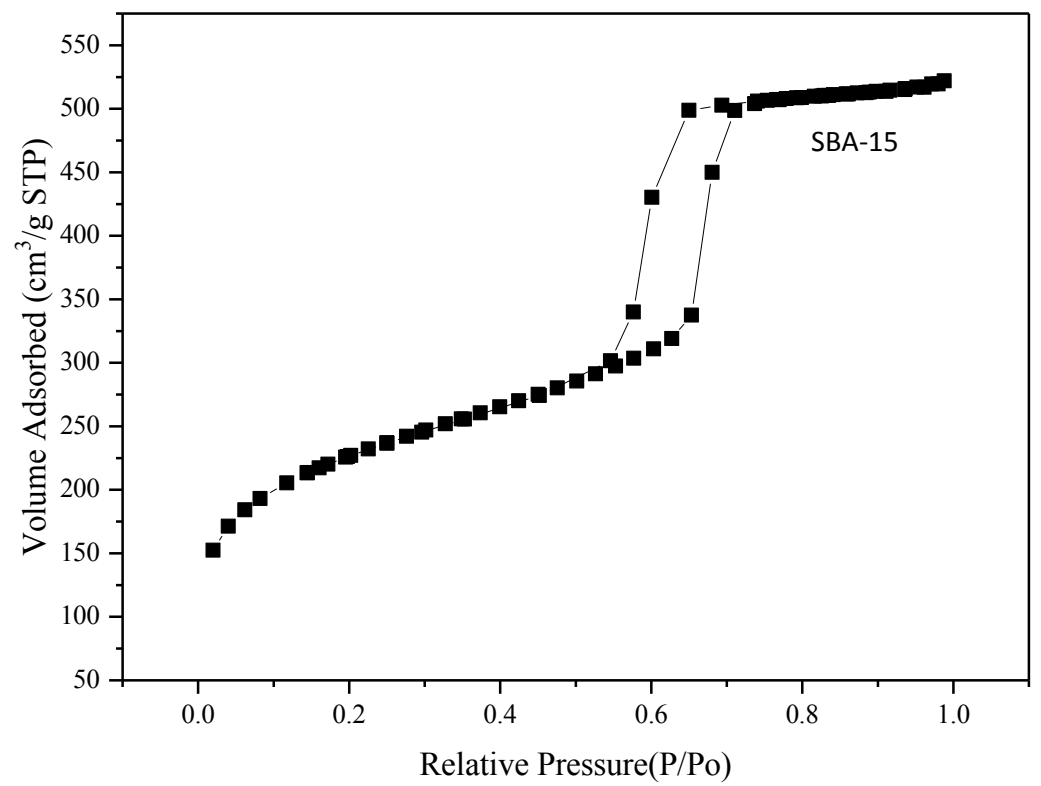

Figure S5 adsorption/desorption isotherm plot of the SBA-15 sample

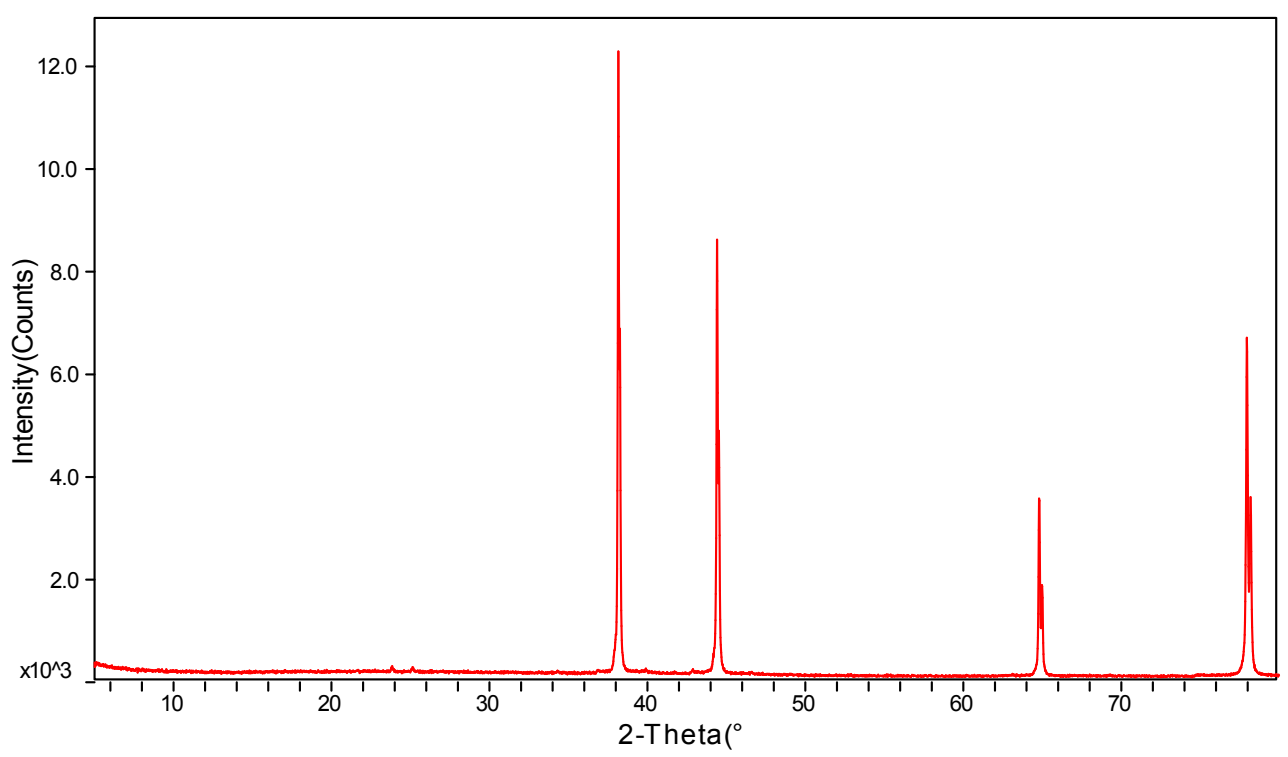

Figure S6 XRD pattern of the aluminium sample holder 


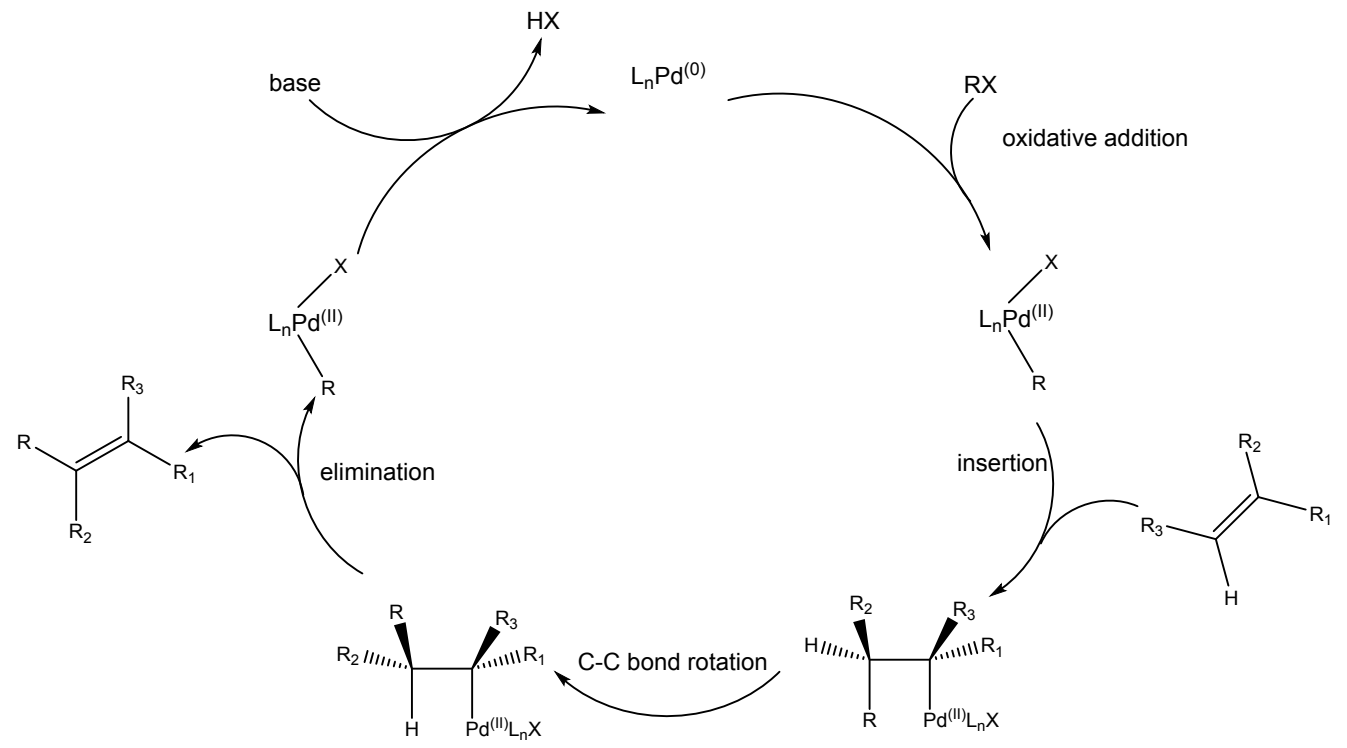

Figure S7 General catalytic cycle for Heck coupling reaction

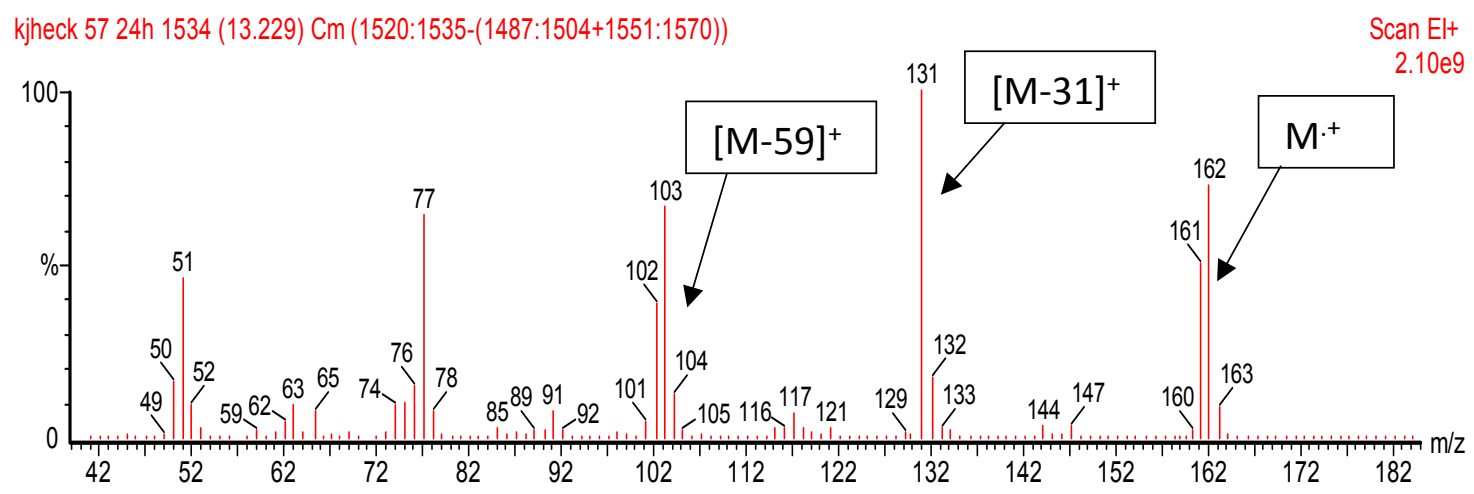

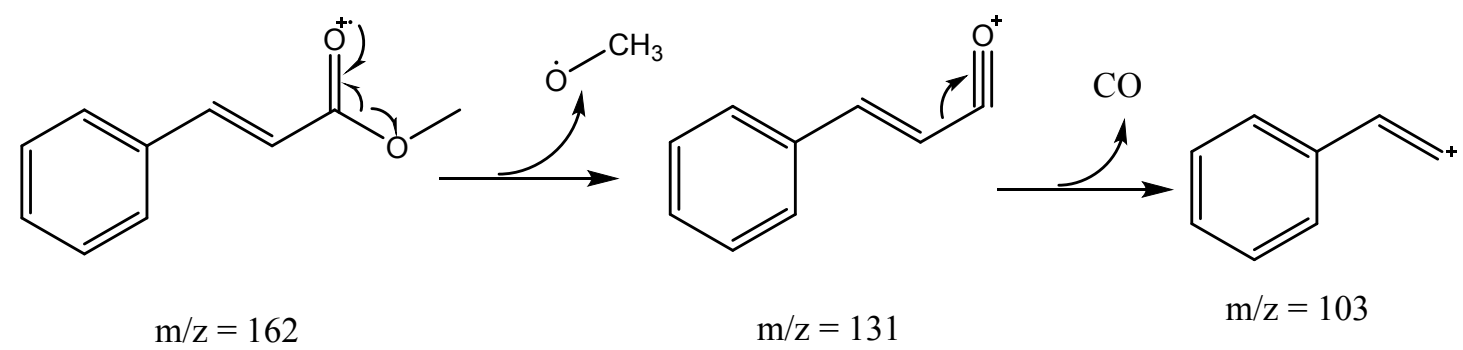




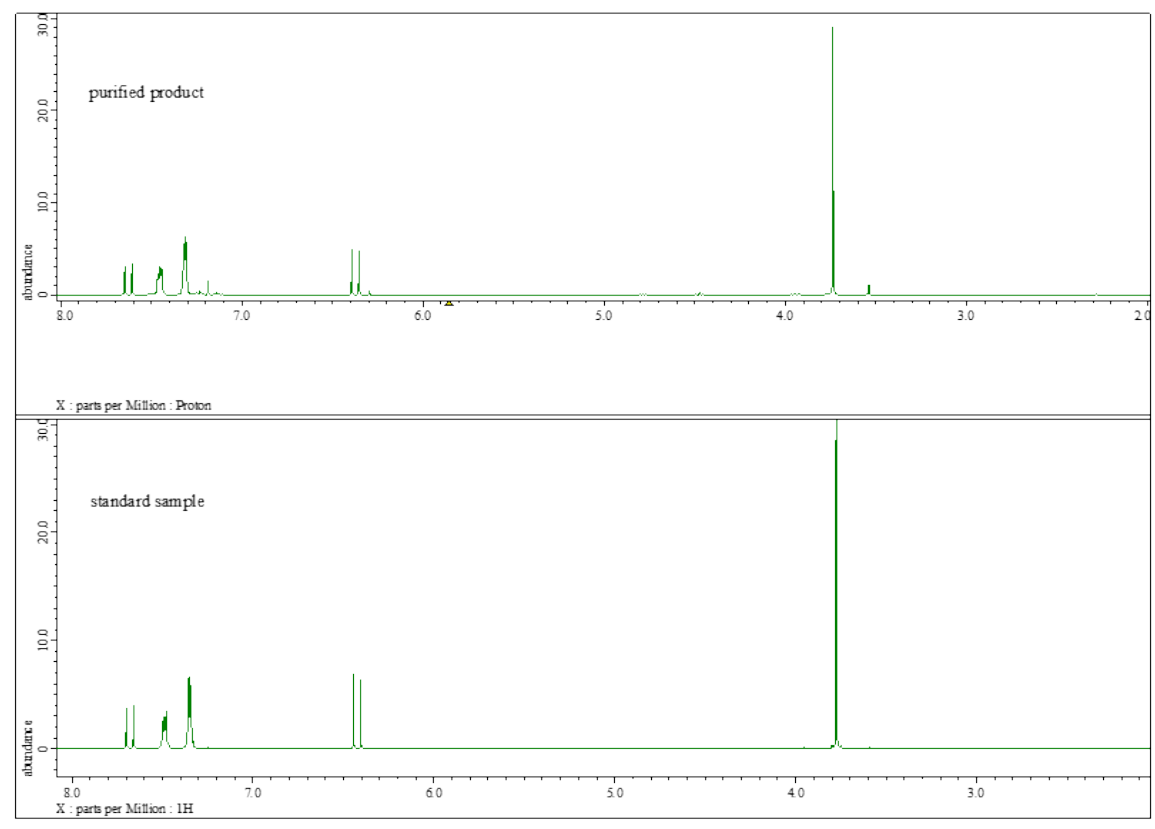

\begin{tabular}{lll}
\hline Proton & $\begin{array}{l}\text { Chemical } \\
\text { shift/ppm }\end{array}$ & Integration, J \\
\hline 1 & 3.73 & $\mathrm{~s}, 3 \mathrm{H}$ \\
2 & 6.37 & $\mathrm{~d}, 1 \mathrm{H}$ \\
3 & 7.62 & $\mathrm{~d}, 1 \mathrm{H} / \mathrm{J}=16 \mathrm{~Hz}$ \\
$4,4^{\prime}$ & 7.45 & $\mathrm{~m}, 2 \mathrm{H}$ \\
$5,5^{\prime}$ & 7.32 & $\mathrm{~m}, 2 \mathrm{H}$ \\
6 & 7.30 & $\mathrm{~m}, 1 \mathrm{H}$ \\
\hline
\end{tabular}

Figure S8 EI Mass spectra of methyl cinnamate and Formation of fragment ions $\mathrm{m} / \mathrm{z}=131$ and $\mathrm{m} / \mathrm{z}=103 ;{ }^{1} \mathrm{H}$ NMR analysis of as synthesized and standard methyl cinnamate

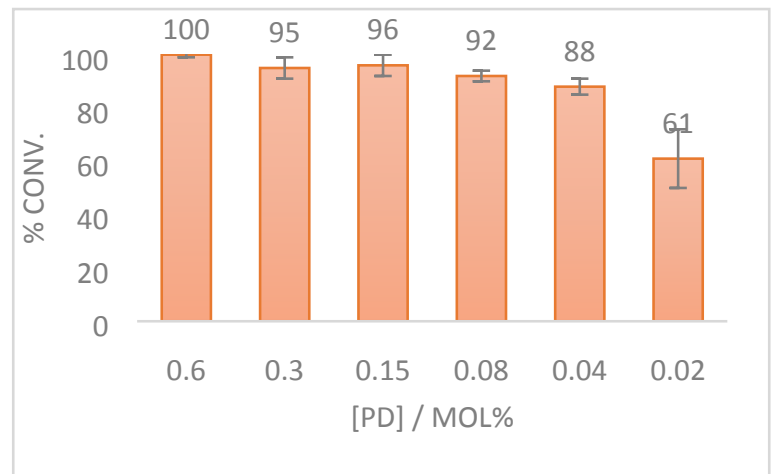

Figure S9 Conversion rate of the Heck reaction using different amounts of P-1 sample in PC 